\title{
Research Paper \\ Structural Model of Academic Conscientiousness Based on Social Adequacy with the Mediating Role of Academic Engagement
}

\author{
Rojina Ahmadpour ${ }^{1}$, Nezam Hashemi ${ }^{* 2}$, Masoud Najari ${ }^{3}$, Mohamad Armand ${ }^{4}$ \\ 1. M.A. in Curriculum Planning, Science and Research Branch, Islamic Azad University, Tehran, Iran \\ 2. Associate Professor, Department of Psychology, Amin Police Academy, Tehran, Iran
}

3. Ph.D. in Educational Psychology, Bukan Center, University of Applied Science and Technology, Bukan, Iran

4. Associate Professor, Department of Curriculum Planning, Institute for Research and Development in the Humanities (SAMT),

Tehran, Iran

Citation: Ahmadpour R, Hashemi N, Najari M, Asadi Armand M. Structural model of academic conscientiousness based on social adequacy with the mediating role of academic engagement. J Child Ment Health. 2021; 8 (2):107-119.

URL: http://childmentalhealth.ir/article-1-1119-en.html
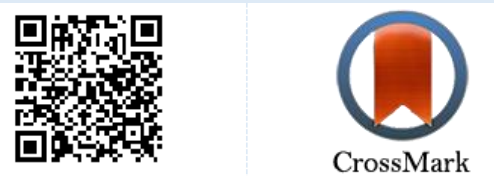

do: $10.29252 / \mathrm{jcmh} .8 .2 .107$

20.1001.1.24233552.1400.8.2.8.9
A R T I C L E I N F O

\section{Keywords:}

Academic

conscientiousness, social adequacy, academic engagement, students

Received: 13 Mar 2021

Accepted: 6 Jun 2021

Available: 22 Sep 2021

\section{A B S T R A C T}

Background and Purpose: Academic conscientiousness is the best predictor of personality for professional, educational, and academic performance. Therefore, the purpose of this study is to provide a model of academic conscientiousness based on social adequacy through the mediation of academic engagement in female high school students.

Method: The method of this research was descriptive-correlational modeling of structural equations. The statistical population includes all-female high school students in Bukan County $(\mathrm{N}=1400)$ who were studying in the 2019-2020 academic year. The sampling method was multi-stage cluster. The sample size was 300 participants. For data collection, Mcllroy and Banting's Academic Conscientiousness Questionnaire (2002), Academic Adequacy Questionnaire (Felner et a, 1990), and Fredricks, Blumenfeld, and Pari's School Engagement Questionnaire (2004) were used as assessment tools. Data analysis was performed by Pearson's correlation method and structural equation modeling by using the SPSS 23 software and LISREL 8.8.

Results: Findings showed that the direct path of social adequacy to academic conscientiousness ( $\beta=$ $0.45, p<0.001)$, academic engagement to academic conscientiousness $(\beta=0.60, p<0.001)$, academic engagement to social adequacy $(\beta=0.63, \mathrm{p}<0.001)$ and the indirect path of social adequacy to academic conscientiousness mediated by academic engagement $(\beta=0.42, p<0.001)$ were positive and significant. Fit indices equal to $\mathrm{CFI}=0.97, \mathrm{NFI}=0.95, \mathrm{FIFI}=0.93, \mathrm{AGFI}=0.90, \mathrm{RMSEA}=$ $0.074, p=0.001$, which shows that the assumed model had a relatively good fit with the data.

Conclusion: Based on the results obtained, social adequacy was directly and indirectly related to academic conscientiousness through academic engagement, and social adequacy and academic engagement can be a good predictor of academic conscientiousness. The results of this study contain important practical implications for improving students' academic conscientiousness.

* Corresponding author: Nezam Hashemi, Associate Professor, Department of Psychology, Amin Police Academy, Tehran, Iran.

E-mail: Nh13450217@yahoo.com

Tel: (+98) 2148931863

2476-5740/ (C) 2021 The Authors. This is an open access article under the CC BY-NC-ND license

(https://creativecommons.org/licenses/by-nc-nd/4.0/). 


\section{Quarterly Journal of}

\section{Extended Abstract}

\section{Introduction}

Academic life is one of the most influential periods of a person's life. It leads to fruitful education and learning (1). Nowadays, the academic achievement of students in the school environment depends on their level of academic conscientiousness. Dutifulness is a subset of conscientiousness that is one of the five big factors of personality traits (2). Conscientiousness is a considerable predictor of personality for occupational, educational, and academic performance $(3,4)$. Conscientiousness is an internal factor that controls human behaviors and thought (5). One of the variables associated with academic conscientiousness is social adequacy. Social adequacy is of particular importance during adolescence; because this period is accompanied by physiological changes and physical maturity on the one hand, and on the other hand, adolescents face unprecedented challenges in their social environment (12). Social adequacy is a series of abilities that lead to construct socializing and beneficial relationships, friendship, and intimacy with peer groups. Social adequacy is a concept that helps children to manage different situations (13). Academic engagement probably plays a mediating role in the relationship of social adequacy and academic conscientiousness. The academic engagement interestingly is a scope of research in recent years. Academic enthusiasm refers to the amount of energy expended in doing academic work and the effectiveness and efficiency that results (22). What is certain is that paying attention to the variables affecting academic conscientiousness, such as social adequacy and academic engagement in students, will lead to the excellence of students' performance and, consequently, the improvement of the educational system. Therefore, conducting this research can lead to more knowledge of the variables affecting academic achievement and ultimately increase student performance. According to the basic role of students lack of academic conscientiousness of students can lead to many problems for both school and students. Therefore, the purpose of this study is to provide a model of academic conscientiousness based on social adequacy through the mediation of academic engagement in female high school students.

\section{Method}

The method of this research was descriptive-correlational modeling of structural equations. The statistical population includes all-female high school students in Bukan County $(\mathrm{N}=$ 1400) who were studying in the 2019-2020 academic year. The sampling method was multi-stage cluster. The sample size was 300 participants. In this way, Bukan city (West Azerbaijan Province) initially is divided into five parts north, south, east, west, and center and then two schools from each region, and from each school, one of the grades is randomly selected, and in each grade 1 class, a total of ten classes was selected. Since the minimum sample size for modeling research is 300 people (32). Therefore, 320 questionnaires were collected and due to the distortion and non-response of some of the questionnaires, the number of questionnaires reached 300 . For data collection, McIlroy and Banting's Academic Conscientiousness Questionnaire (7), Felner et al. academic adequacy questionnaire (16), and Fredricks, Blumenfeld, and Pari's school engagement questionnaire (24) were used as assessment tools. It should be noted that the validated version of these tests in Iran has been used to conduct this research. Data analysis was performed by Pearson's correlation method and structural equation modeling by using the SPSS 23 software and LISREL 8.8 .

\section{Results}

Before data analysis, the default normality was checked based on the Kolmogorov-Smirnov test, and the data were assumed to be normal. The mean age and standard deviation of the age for female students were 1.74 . 16.34, respectively. The results showed that there is a positive and significant correlation between all components of research variables. All components of research are significant at the level of 0.01 and the direct path of social adequacy to academic conscientiousness $(\beta=0.45, p$ $<0.001$ ), Academic enthusiasm to academic conscientiousness ( $\beta=0.60, p<0.001)$, academic engagement to social adequacy $(\beta=0.63, p<0.001)$ and Indirect path of social adequacy to academic conscientiousness mediated by academic engagement $(\mathrm{B}=0.42, \mathrm{p}<0.001)$ was positive and significant. Fit indices equal to $\mathrm{CFI}=0.97, \mathrm{NFI}=0.95, \mathrm{FIFI}=0.93, \mathrm{AGFI}$ $=0.90$, RMSEA $=0.074, p=0.01$, which shows that the assumed model had a relatively good fit with the data.

\section{Conclusion}

The results showed that the proposed model fits well with the data collected from female high school students. The results also showed there are significant relationships between academic conscientiousness and social adequacy and academic engagement. Analysis of structural relationships illustrated that social adequacy and academic engagement directly and significantly had effects on the students' academic conscientiousness. The findings of this study were consistent with the results (9-11) which also showed that there is a relationship between academic conscientiousness and social adequacy and students' academic engagement. Explaining the finding that social adequacy can predict academic conscientiousness, it can be said that social adequacy improves students' adaptive behavior, communication, life, and social skills. Social adequacy is a technique thst people learn to improve their competency while being able to interact appropriately in different situations. Social adequacy includes the ability of individuals to act in a way and manner appropriate to age and cognitive ability, including factors such as selfawareness, social awareness, self-management, communication and interaction skills, and decision-making responsibility (31). 


\section{Quarterly Journal of Child Mental Health}

Vol. 8, No. 2, Summer 2021

In the present study, the use of self-assessment tools has limited the generalization and inference of results. Other limitations of the research include the location and scope of the research in Bukan city and public schools. It is suggested that a study be conducted on students of different age groups, various levels of education, in different cities. It is also suggested that in future research, the role of contextual variables (subject age, place of residence, parental income, gender, etc.) be considered as a moderating variable.

\section{Ethical Considerations}

Compliance with ethical guidelines: This research has been done with the permission of Education Department No. $312033 / 58 / 653$. Other ethical considerations, such as the complete consent of the sample and the observance of the principles of confidentiality and confidentiality of information, are also considered.

Funding: This study was conducted without the support of organizational and financial institutions.

The role of each of the authors: The first author is in charge of compiling the article, the second author is the supervisor and the third and fourth authors are in the role of research consultants.

Conflict of interest: The authors declare there was no conflict of interest in this study, and this study was conducted without the support of organizational and financial institutions.

Acknowledgments: We thank the management and staff of the county education department and all the teachers and students who helped us carry out this research. 


\title{
مدل ساختارى وجدان تحصيلى بر اساس كفايت اجتماعى با نقش ميانجى اشتياق تحصيلى
}

\author{
روزينا احمديور'، نظام هاشمى"'، مسعود نجارى"، محمد آرمند

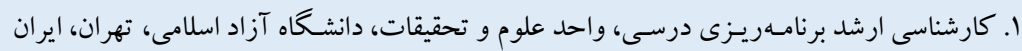

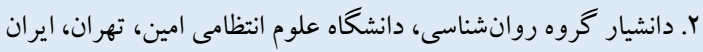

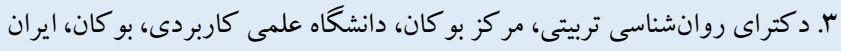

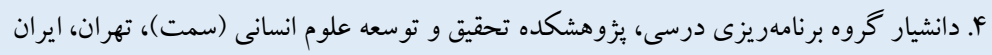

\begin{tabular}{|c|c|}
\hline جكيده & مشخصات مقاله \\
\hline زمينه و هدف: وجدان تحصيلى يكى از بيشيينى كنندهاى شـخصيت براى عملكرد شـلى، آموزشى، و تحصيلى اسـت. بدين ترتيب & 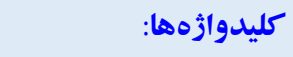 \\
\hline يُزوهش حاضـر با هدف ارائه مدل سـاختارى وجدان تحصيلى بر اسـاس كفايت اجتماعى با نقش ميانجى اشتياق تحصيلى در دانش آموزان & 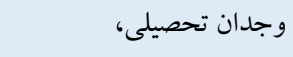 \\
\hline 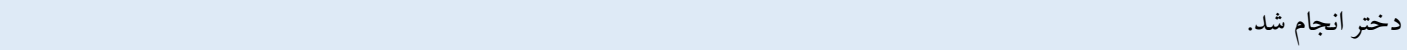 & 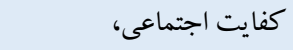 \\
\hline روش: روش يُزوهش توصيفى از نوع همبستخى و مدل يابى معادلات ساختارى بود. جامعه آمارى يُزوهش شامل تمامى دانش آموزان دختر & اشتياق تحصيلى، \\
\hline 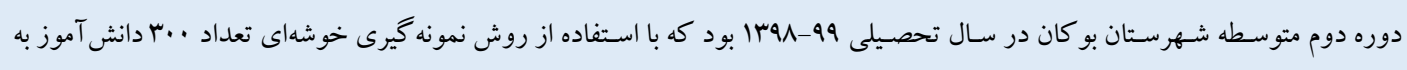 & دانش آموزان \\
\hline 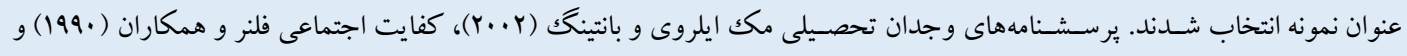 & \\
\hline 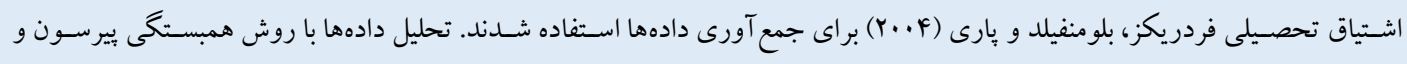 & \\
\hline مدل يابى معادلات ساختارى و با استفاده از نرم افزار بץ SPSS و LISREL N/^ انجام شد. & \\
\hline 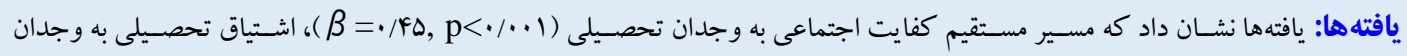 & \\
\hline 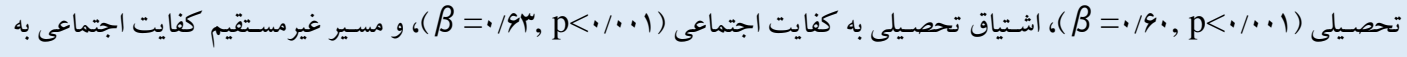 & \\
\hline 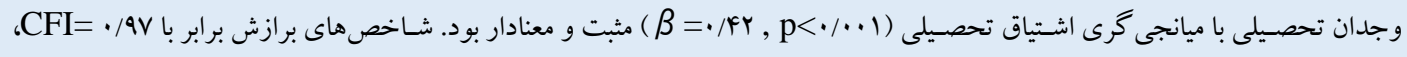 & \\
\hline 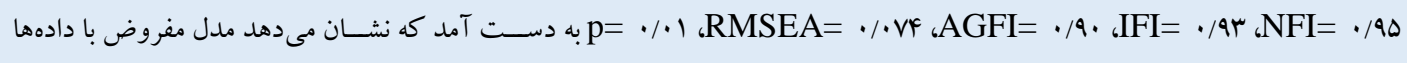 & \\
\hline 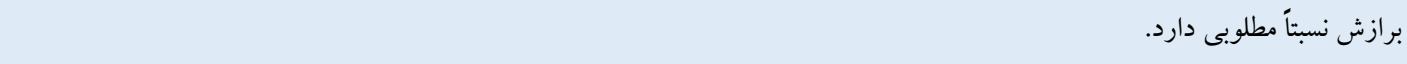 & \\
\hline نتيجه كيرى: بر اسـاس نتايج به دسـت آمده كفايت اجتماعى هم به صسورت مستقيم و هم به صسورت غيرمستقيم با ميانجى گرى اشستياق & 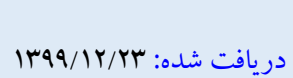 \\
\hline تحصيلى با وجدان تحصيلى در ارتباط است. نتايج اين يثوهش حاوى تلويحات كاربردى مهمى براى ارتقاى وجدان تحصيلى دانش آموزان & 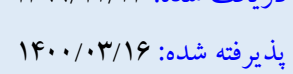 \\
\hline در مدا & 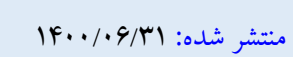 \\
\hline
\end{tabular}

* نويسنده مسئول: نظام هاشمى، دانشيار گروه روانشناسى، دانشكاه علوم انتظامى امين، تهران، ايران.

رايامه: Nh13450217@yahoo.com

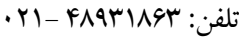


هدف تسلط گرايشى و عملكرد گرايشى مى تواند فرسودگى تحصيلى را

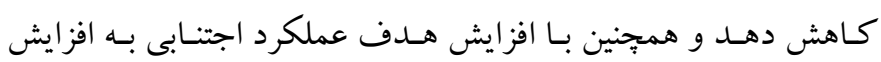

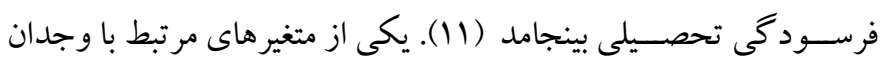

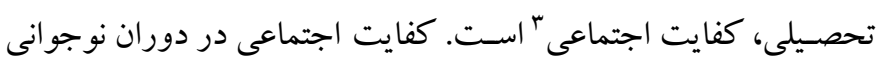

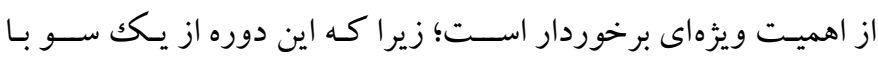

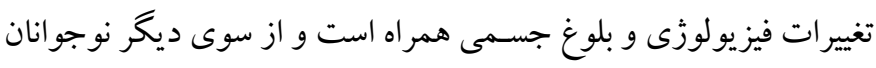
با كشـاكش هاى جديدى در محيط اجتماعى خود مو اجه مىشـوند (Y I I).

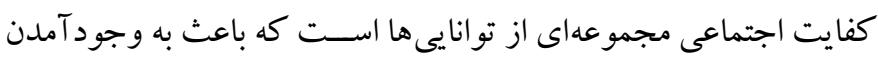

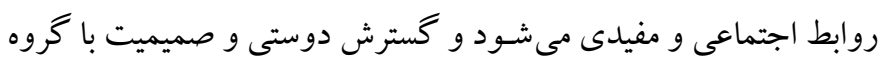

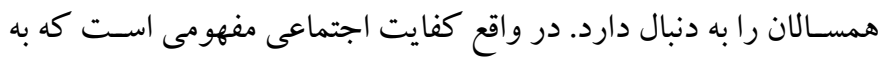

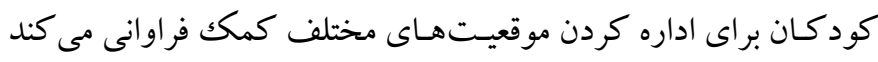

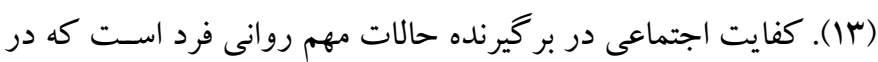

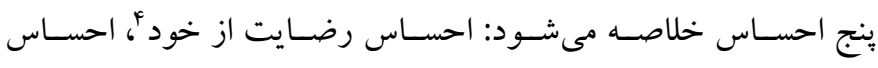

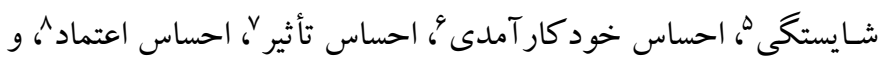

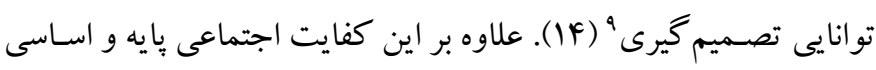

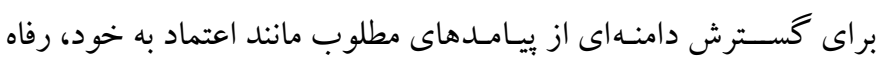

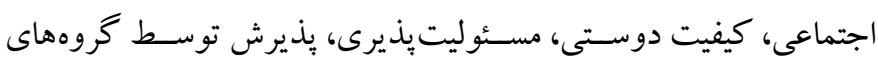

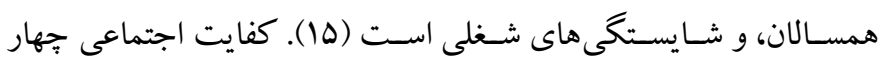

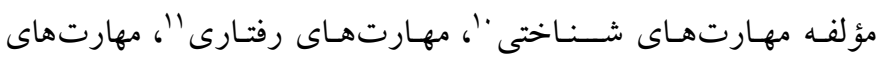

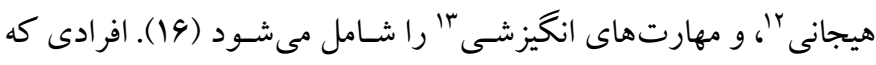

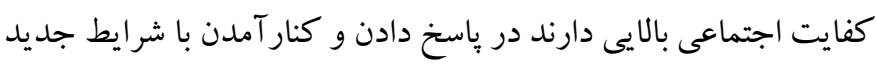

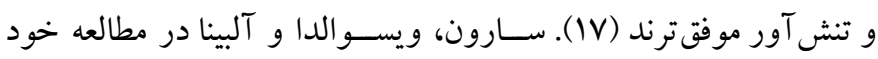

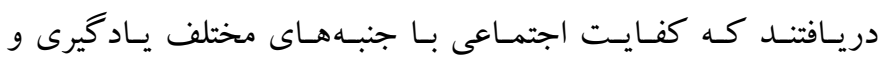
سـازش يافتكى در مدرسـه ارتباط دارد (1) (1). بسـيارى از مطالعات ديخر

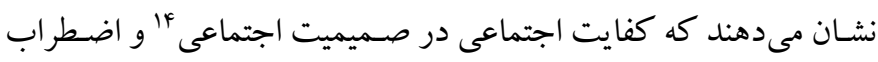

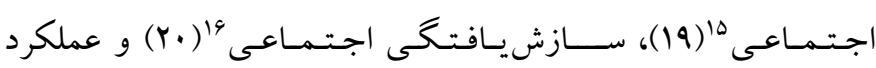
تحصيلى اV (Y) نقش دارد.

10. Cognitive skills

11. Behavioral skills

12. Emotional skills

13. Motivational skills

14. Social intimacy

15. Social anxiety

16. Social adjustment

17. Academic performance
مقلمها

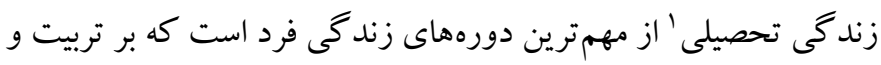

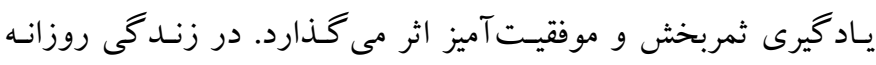

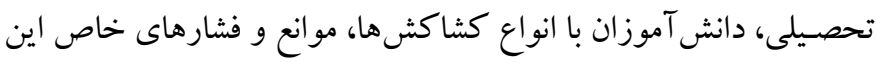

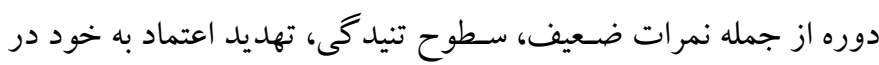

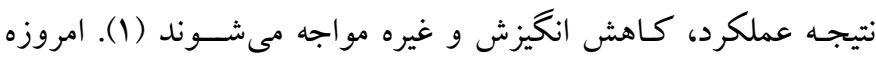

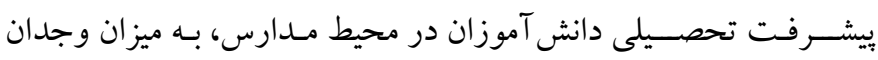

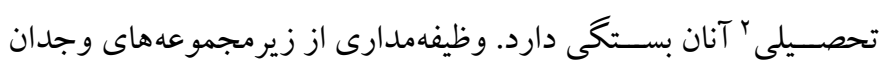
اسـت كه جزء ينج عامل بزر گك صفات شخصيتى محسوب مى شود (Y) (Y).

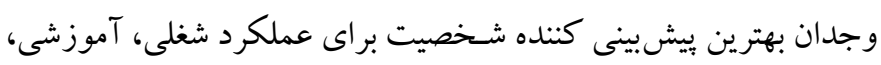

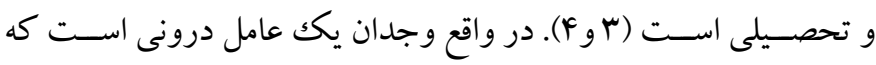

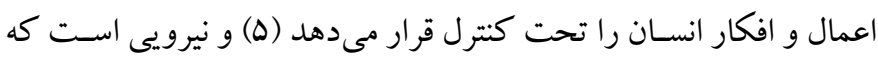

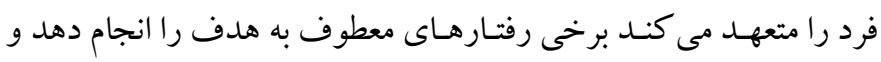

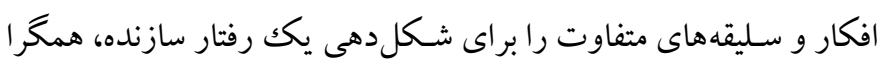

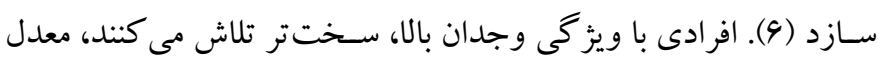

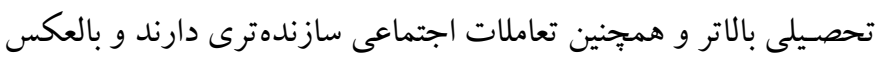

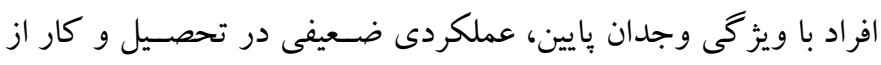

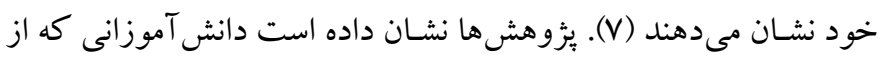

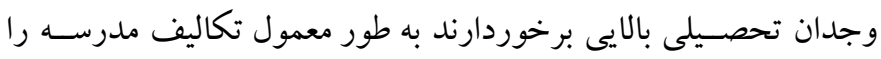

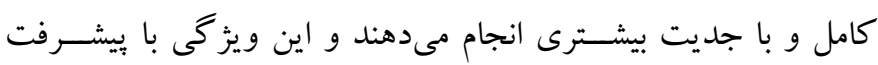
تحصيلى در ارتباط است (^). در بزؤهشى فطين، حسينيان، اصغرنز ادفريد و ابو المعالى دريافتند كه

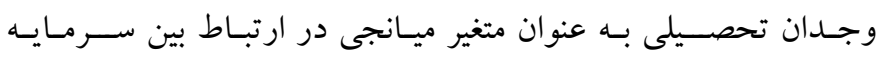

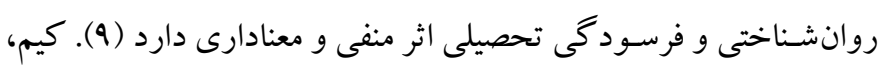

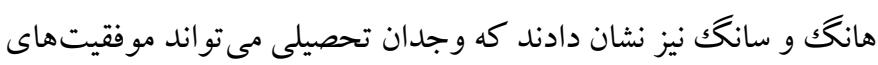

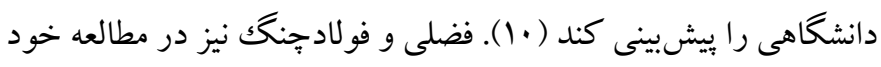

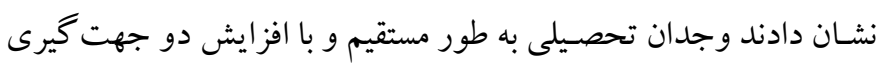

1. Academic life

2. Academic conscientiousness

3. Social adequacy

4. Feeling satisfied

5. Feeling competent

6. Feeling of self-efficacy

7. Feeling the impact

8. Feeling confident

9. Ability to make decisions 
اشـياق تحصيلى را بيشبينى مى كند؛ و در مجموع سرزندگى تحصيلى

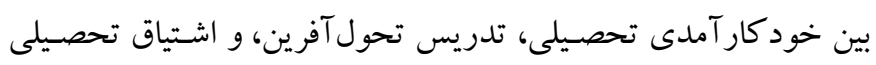

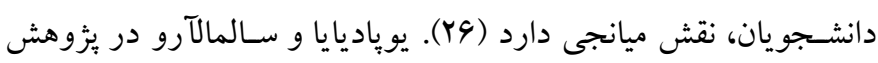

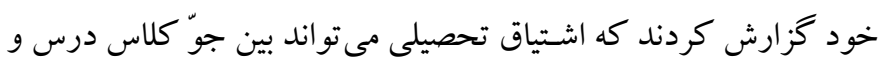

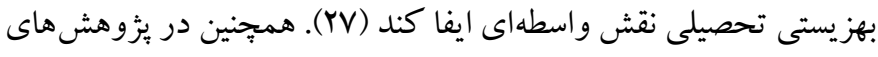

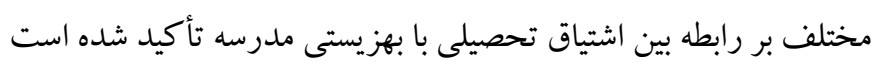

( $(\mathbf{I}-\mathrm{YN})$

آنجهه مسـلم اسـت توجه به متغيرهاى اثر گذار بر وجدان تحصسيلى از

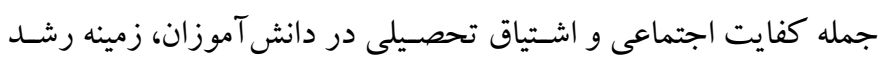

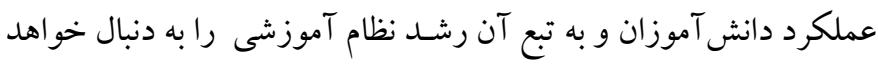
داشـت. در نتيجه انجام اين ئزوهش مى تو اند به شـناخت بيشـتر متغيرهاى اثر كذار بر موفقيت تحصسيلى و در نهايت افزايش عملكرد دانش آموزان

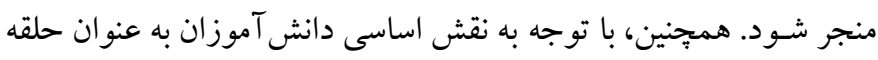

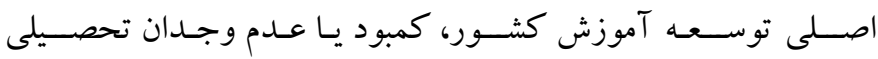

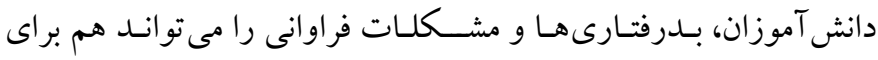

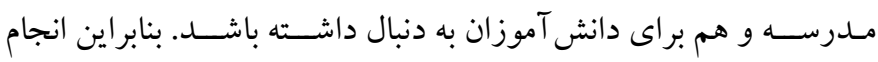

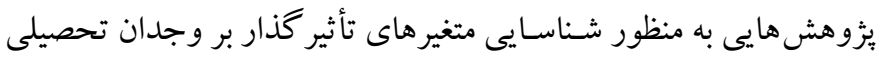

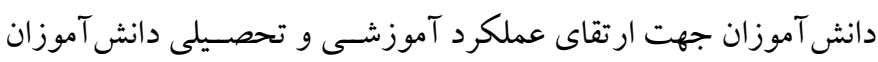
ضـرورى به نظر مىرســـ. بنابر اين هدف از انجام اين ئزوهش اروائه مدل

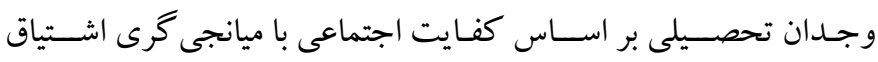
تحصيلى در دانش آموزان دختر دوره متوسطه است. بر همين اساس مدل مفهومى ئزوهش به صورت نمودار إيشنهاد مى لشود.

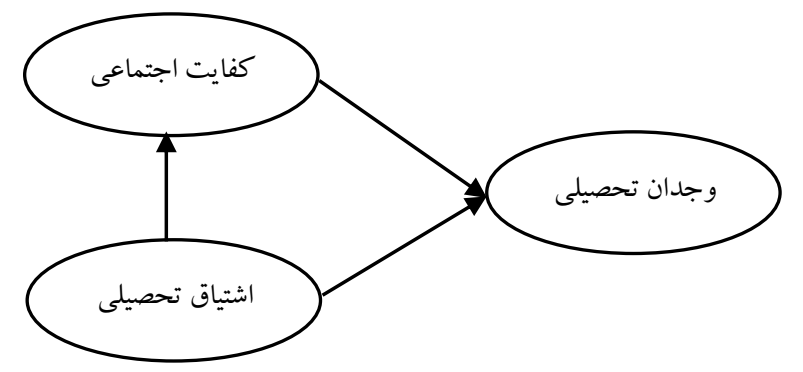

نمودار 1: مدل مفهومى يخوهش
عاملى كه مىتواند بين كفايت اجتماعى و وجدان تحصسيلى نقش ميانجى را ايفا كند، اشتياق تحصيلى' است. اشتياق تحصيلى كه در جند

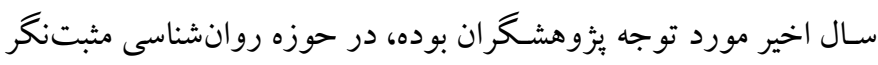

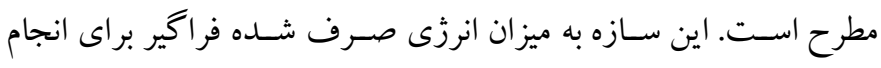

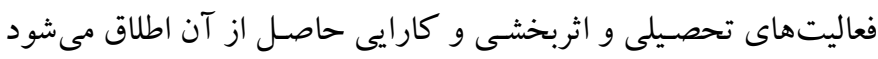

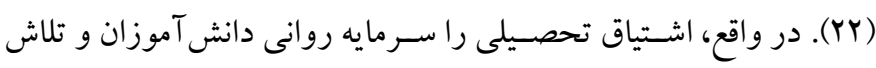

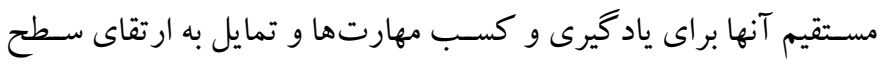

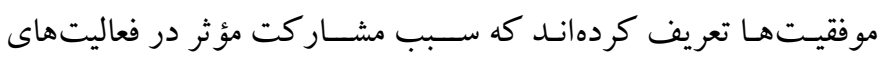
مدرسه، شر كت در فعاليتهاى كلاسى، سازش يافتخى با فرهنگك مدرسه،

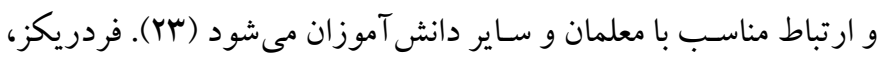

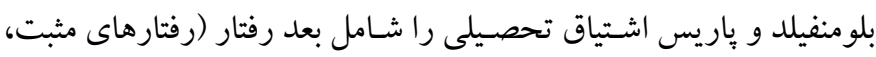

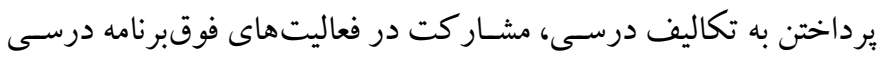

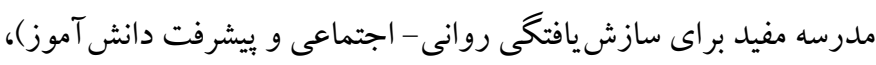

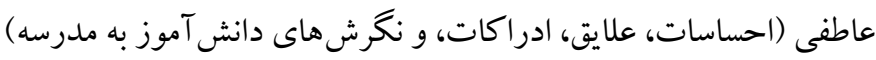

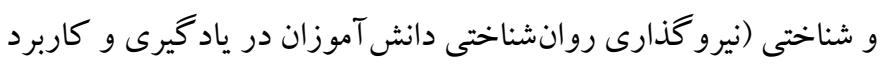

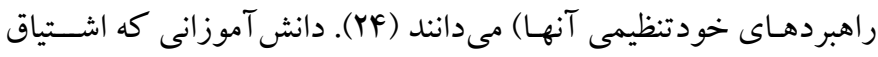
تحصيلى بالاترى دارند، توجه و تمر كز بيشـترى بر مسائل و موضوعات بال

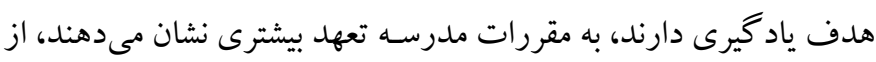

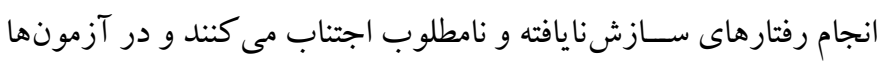

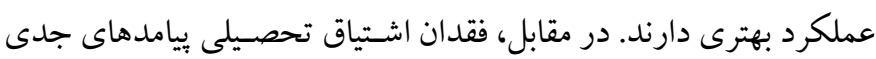

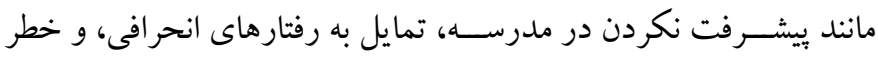

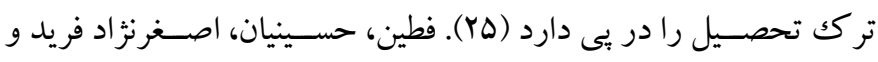

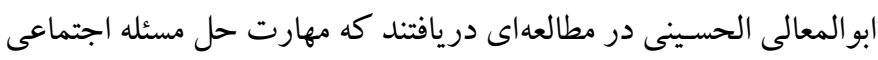

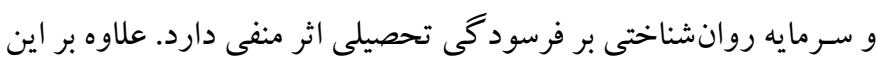

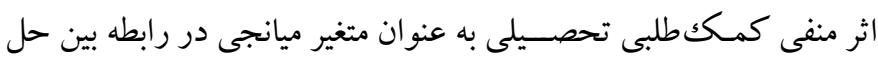

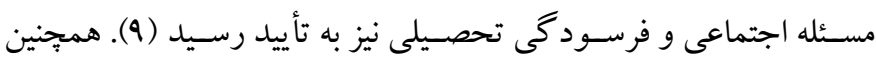

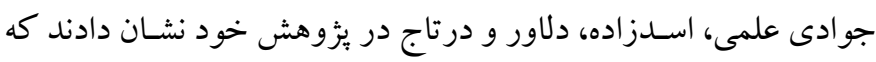
خود كار آمدى تحصيلى بو تدريس تحول آفرين بر اشتياق تحصيلى اثر

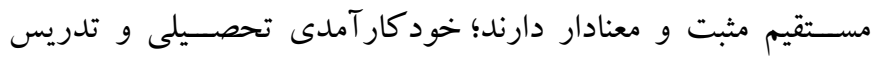

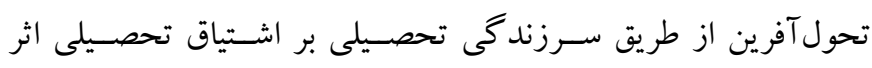

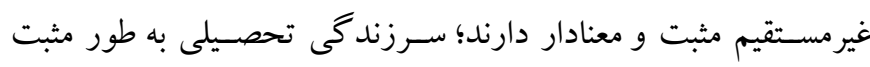
1. Academic engagement

\section{Academic engagement}


(V). در يُزوهش حاضر نيز مقدار آلفاى كرونباخ r/1/ محاسبه شده است و روايى برسشنامه با نظرخواهى از متخصصان مورد تأييد قرار كرفت.

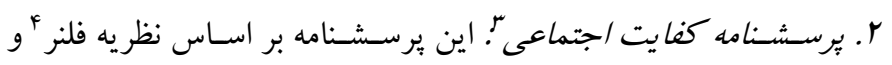
همكاران در سـال •199 و با هدف سـنجش ميزان كفايت اجتماعى تهيه شـده اسـت كه شـامل FV كويه و جهار مقياس مهارت شـناختى، مهارت رفتارى، كفايت هيجانى، و آمايه انخيزشـى تقســيم مىشــود. شــيوه نمره گذارى آزمون با اســفاده از يكك مقياس V درجهاى از ا (كاملاً

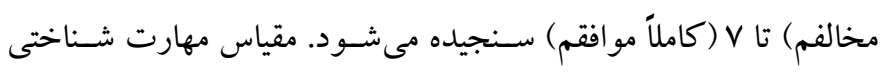
شامل ب گويه و حداقل ب نمره و حداكثر اY نمره، مقياس مهارت رفتارى

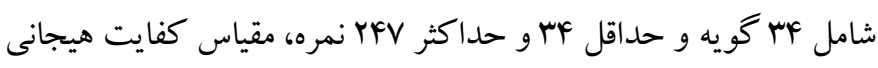
شــامـل ب كويـه و حداقل ب نمره و حداكثر اY نمره، و مقياس آمايه

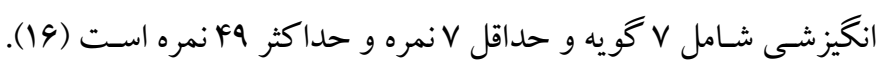
اين يرسـشـنامه توسـط يرندين هنجاريابى شـده كه ضـريب اعتبار آن با

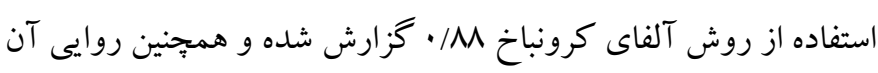
با استفاده از روش تحليل عاملى تأييد شده كه مقدار كفايت نمونهبردارى

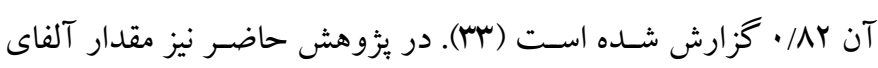
كرونبـاخ براى مؤلفـهــاى مهـارت شــــاختى (VD/•)، مهارت رفتارى

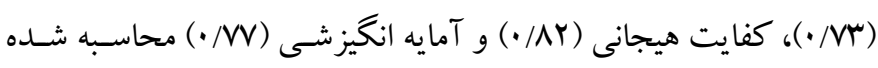
است و روايى صورى و محتو ايیى برسشنامه با نظرخو اهى از متخصصان به صورت كيفى مورد تأييد قرار گرفته است. r. برسشنامه /شتياق تحصيلى ه. اين برسشنامه توسط فردريكز و همكاران در سال \& + . ب و با هدف سنجش ميزان اشتياق تحصيلى تدوين شده است

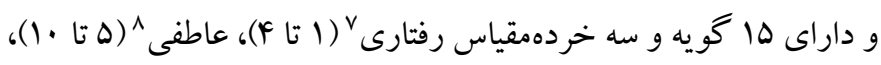

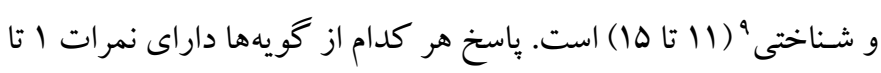
هاست كه از هر گز تا هميشه را شامل مى شود. حداقل و حداكثر نمره و نقطه برش در كل برسـشـنامه اشـتياق تحصـيلى به ترتيب ها، VD و VD اسـت. نمره يايين تر در اين خرسشــامه نشـاندهنده اشتياق تحصيلى كم و

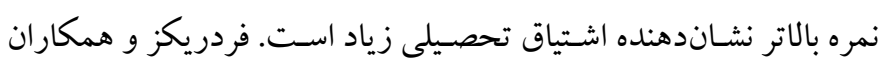
ضـريب اعتبار اين يرسـشـنامه را از طريق روش آلفاى كرونباخ وی/.

6. Fredricks

7. Behavioral

8. Emotional

9. Cognitive

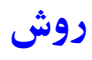
الف) طرح بزوهش و شر كت كنند كان: روش اين يزوهش توصيفى -

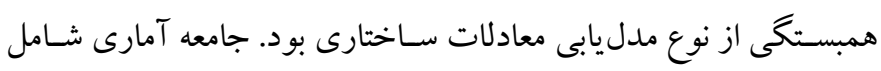

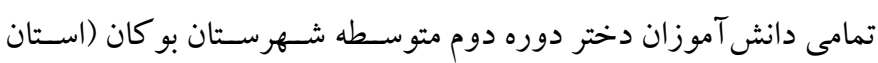

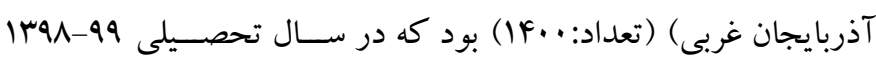

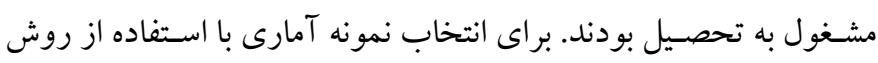

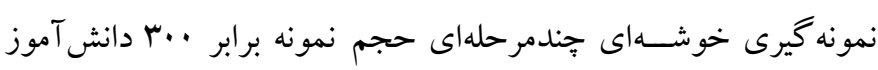

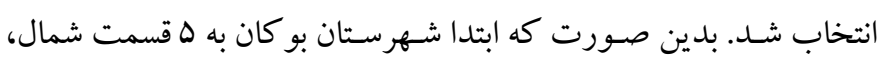

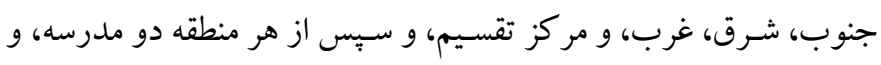

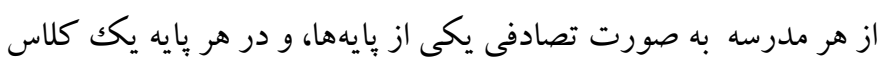

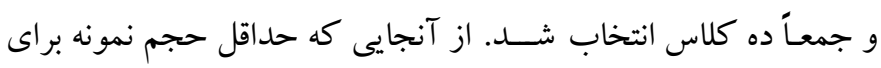

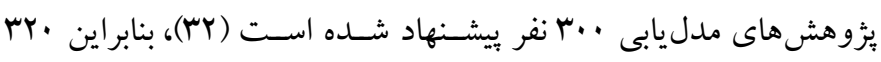

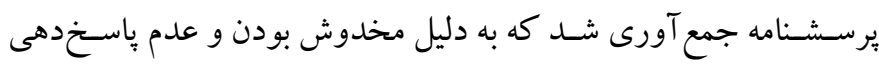

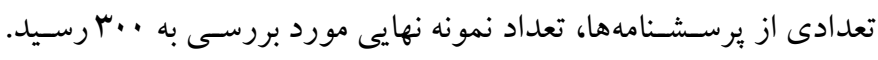

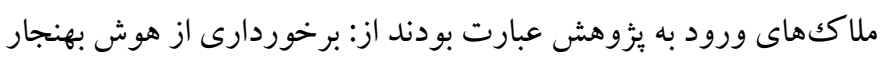

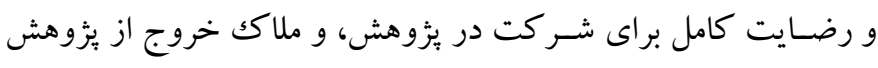

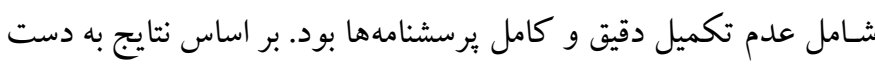

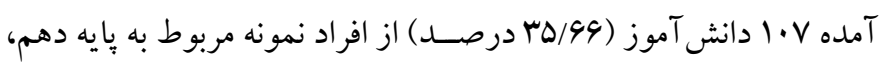

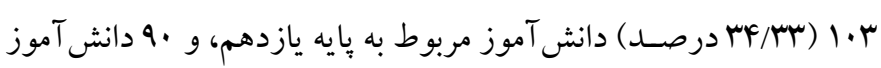
( • درصد) مربوط به يايه دوازدهم بودند.

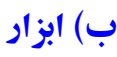

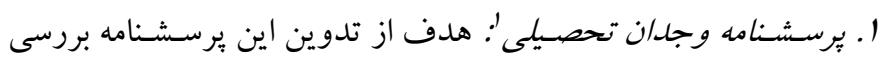

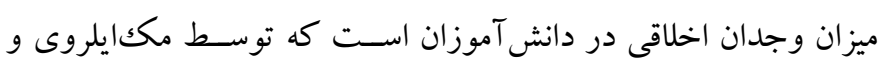

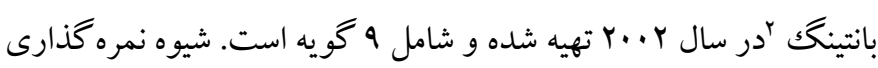

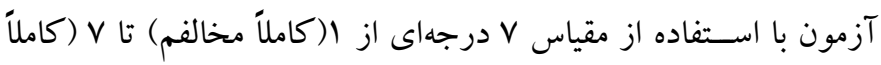

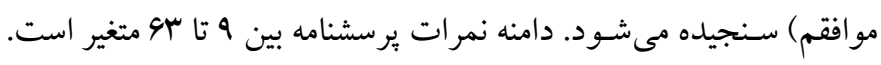

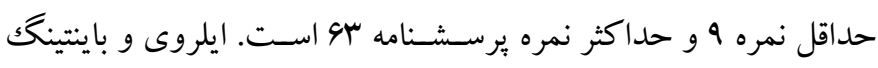

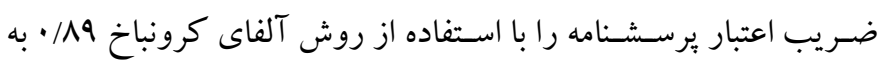

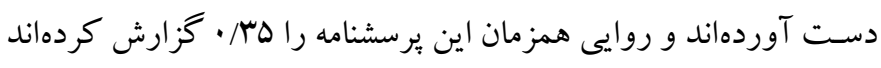

1. Academic conscientiousness questionnaire

2. McIllory \& Bunting

3. Social adequacy questionnaire

4. Felner

5. Academic engagement questionnaire 
همجينين از آنها خواسته شد كه نخست توضيحات ابتدايى مربوط به نحوه ياسخ گويى به وبرسشنامه ها را مطالعه كرده، سيس با نهايت حوصله و دقت

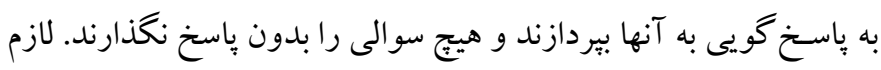

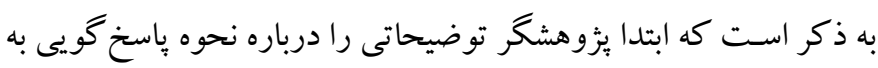
سوالات و زمان ياسخ گويى به برسشنامهها ارائه كرد. براى تحليل دادهها شـاخصهاى آمار توصيفى شامل ميانكين و انحر اف معيار به كار رفت. تحليل دادهها با روش همبستخى ييرسون و مدل يابى معادلات ساختارى و با استفاده از نرم افزار سب LPSS و LISREL ^/1 انجام شد.

\section{كافته ها}

يبش از تحليل دادهها بررسـى ييشفرض نرمال بودن بر اســاس آزمون كالمو گروف - اسـميرنوف بررسى شد و فرض نرمال بودن دادهها برقرار بود. ميانگين سنى و انحراف معيار سن براى دانش آموزان دختر به ترتيب I/VF士19/MF نمره و بيشــرين نمره مربوط بـه متغيرهـاى بزثوهش در جدول ا خزارش شده است.
گز ارش كردهاند و روايى سـازه و محتو ايیى نيز توسـط سـازند گان تأييد شده است (YY). در بزٔوهش عباسى و همكاران مقدار اعتبار ابزار از طريق روش آلفاى كرونباخ 199 • گزارش شده است (MF) و در يزوهش حاضر

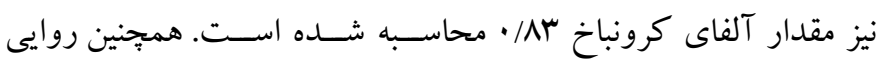
صورى و محتوايى برسشنامه با نظرخواهى از متخصصان به صورت كيفى مورد تأييد قرار كرفته است. ج) روش اجر ا: بعد از دريافت مجوزهاى للام از اداره آموزش و برورش

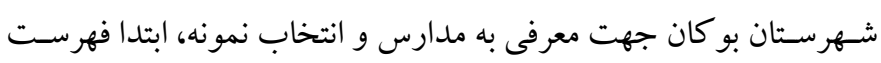
تمامى مدارس دختر انه دوره دوم متوسـطه شـهرسـتان مذكور اخذ شــد. سـبس با روش نمونه گيرى خوشهاى و به شرحى كه در بخش روش ارائه شــــ، افراد نمونه انتخاب شـــه و با اجازه مدير ان مدارس و معلمان و با حضور در كلاسها، برسـشنامهاى بثزوهش در اختيار دانش آموزان قرار داده شـد و تمامى دانش آموزان كلاس ها به برسـشنامههاى بئوهش ياسخ دادند كه در نهايت · . ب برسـشـنامه به طور كامل جمع آورى شـد. جهت جلب همكارى و اعتماد مشـار كت كنند كان، ضـمن برقرارى رابطه حسنه بــه آنها اطمينان خاطر داده شــد كه اطلاعات محرمانه باقى خواهد ماند.

جدول ا: شاخصهاى توصيفى، نتايج آزمون كالموكروف - اسميرنف، و ضرايب همبستغى مربوط به متغيرهاى بزوهش

\begin{tabular}{|c|c|c|c|c|c|c|c|c|c|}
\hline \multicolumn{3}{|c|}{ ضرايب همبستىى } & \multicolumn{2}{|c|}{ كالموكروف - اسمير نف } & \multicolumn{4}{|c|}{ آمار توصيفى } & \multirow{2}{*}{ متغير } \\
\hline$r$ & r & 1 & سطح معنادرى & $\mathbf{Z}$ & بيشينه & كمينه & انحر اف معيار & ميانتين & \\
\hline & & - & $\cdot / T Y F$ & $\cdot / 101$ & $\Delta 9$ & r. & $\mid r / M F$ & $F r / M F$ & وجدان تحصيلى \\
\hline & - & 米然/AFV &.$/$ VVD & - /FrF & ral & lar & IN/Tr & $r r q / \Delta$. & كفايت اجتماعى \\
\hline - & $* * / \wedge / f$ & ***. VFF & $.11 \cdot 0$ & · MYY & $\Delta \Delta$ & 19 & $1 \cdot / r r$ & MN/FG & اشتياق تحصيلى \\
\hline
\end{tabular}

سطح معنادارى برابر با 1+٪.

بنابر اين به لحاظ آمارى معنادار نيسـت (ه • • > P كه نشـان مىدهد هر سـه توزيع نرمال هسـتند. همجيخنين نتايج نشـان داد كه همبسـتخى مثبت و معنـادارى بين تمـامى متغيرهـاى وجــدان تحصــيلى، كفايت اجتماعى، و اشتياق تحصيلى وجود دارد.
در جدول ا نتايج آمار توصيفى، نتايج كالمو گروف - اسميرنف، و ضـرايب همبسـتكى مربوط به متغيرهاى بزٔوهش كز ارش شـده اسـت. با توجـه بـه اينكـه مقـدار ســـح معنـادارى به دســت آمده براى آزمون كالمو گروف - اسـميرنف براى همه متغيرها بزرگكتر از هـ • • اسـتـ، 
جدول r: همبستغى بين خردهمقياس هاى متغيرهاى ثئوهش

\begin{tabular}{|c|c|c|c|c|c|c|c|c|c|c|}
\hline انحراف معيار & ميانكين & $r$ & 7 & 0 & $\varepsilon$ & $r$ & $r$ & 1 & \multicolumn{2}{|c|}{ متغير } \\
\hline $9 / \pi \Delta$ & $\mid V / \cdot F$ & & & & & & & - & مهارت شناختى & .1 \\
\hline $19 / 4 \mathrm{~V}$ & $|V F / A|$ & & & & & & - & 米米. $/ 01$. & مهارت رفتارى & $r$ \\
\hline$\Delta / \wedge r$ & $19 / 0$. & & & & & - & ***. & 米些. 1991 & كفايت هيجانى & r \\
\hline$V / I V$ & $r 1 / 10$ & & & & - & *** $\cdot / N r 4$ & 类类. 191 . & 类䄅・ $\cdot / \Delta \cdot V$ & آمايه انكيزشى &.$f$ \\
\hline$\varphi / \wedge q$ & $11 / F V$ & & & - & ***/ADr & 䄅前・/ADV & $* * / N F V$ & ***/91f & رفتارى & $\Delta$ \\
\hline$\Delta / q$. & $|F / Y|$ & & - & ***/Aqr & $* * / A \cdot r$ & 䄅前. $/ A \Delta F$ & 米光 $\cdot / \Delta V$ & 䄅光. & عاطفى & 4 \\
\hline$\Delta / \cdot V$ & $\mid r / v \Lambda$ & - & ***/AYF & ***/VAY & ***. 1994 & 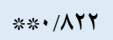 & 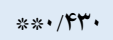 & $* * / \Delta r q$ & شناختى & v \\
\hline
\end{tabular}

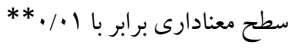

بـا توجسه بـه نتـايج جدول Y همبســتحى مثبت و معنادارى بين تمامى مؤلفه هاى متغيرهاى بثزوهش وجود دارد كه در سطح 1 • • معنادار است.

جدول "ج: شاخصهاى برازندكى مدل ييشنهادى

\begin{tabular}{|c|c|c|c|c|c|c|c|c|c|}
\hline AGFI & NFI & CFI & IFI & DF & RMSEA & $\mathbf{P}$ & $\mathrm{X}^{2} / \mathrm{df}$ & $X^{2}$ & شاخصهاى برازش \\
\hline.$/ 9$. &.$/ 90$ &.$/ 9 V$ & . & 11 & $\cdot / \cdot V^{F}$ &.$/ .1$ & $r / V r$ & $|F| / q V$ & مدل ييشنهادى \\
\hline
\end{tabular}

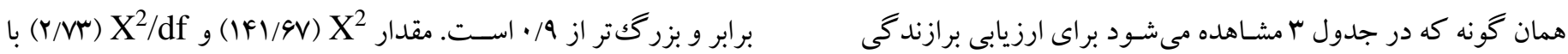

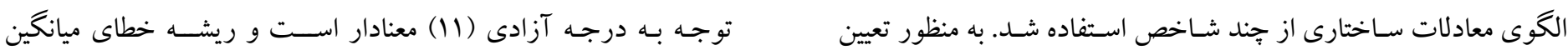

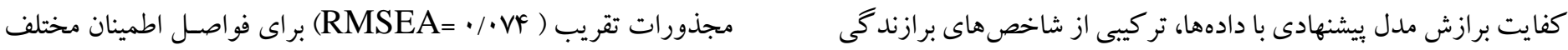

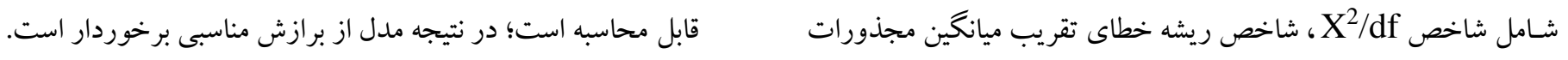

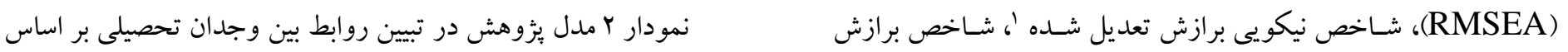

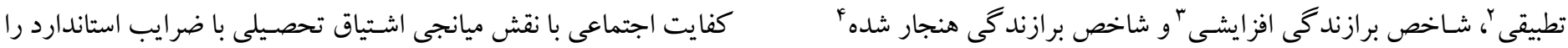

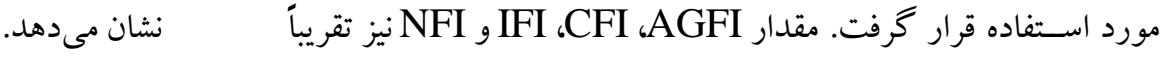

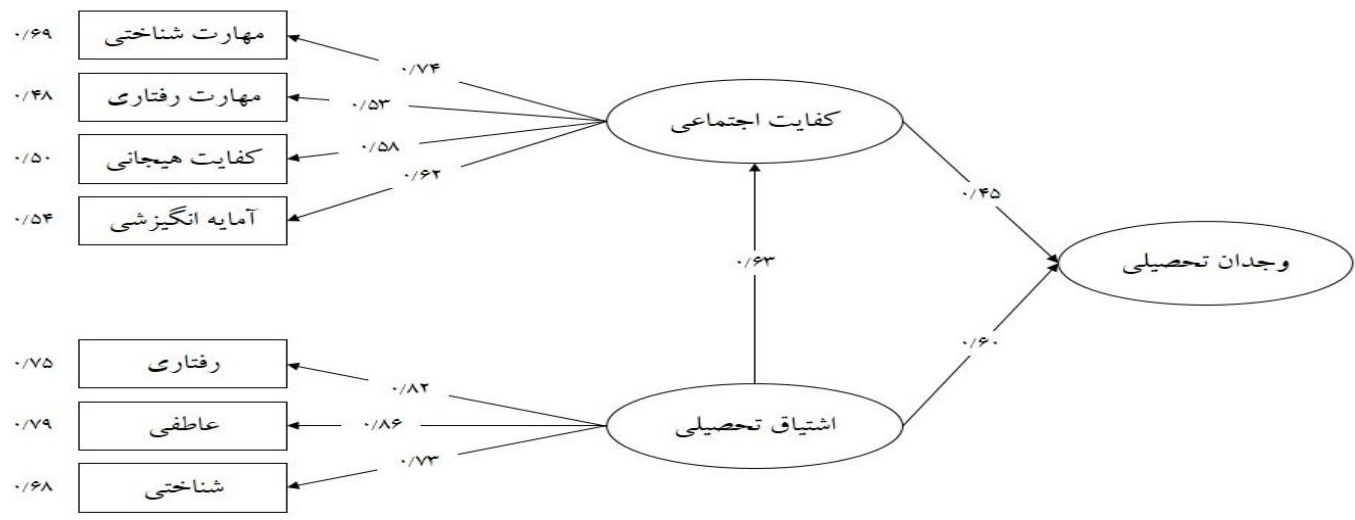

نمودار ז: مدل ئوهش در تبيين روابط بين وجدان تحصيلى بر اساس كفايت اجتماعى با نقش ميانجى اشتياق تحصيلى با ضرايب استاندارد

3. Incremental fit index (IFI)

4. Normed fit iIndex (NFI)
1. Adjusted goodness of fit index (AGFI)

2. Comparative fit index (CFI) 
جدول ع: اثرات مستقيم، غير مستقيم و كل متغيرهاى يخوهش

\begin{tabular}{|c|c|c|c|c|c|}
\hline $\mathbf{P}$ & $\mathbf{T}$ & اثر كل & اثر غيرمستقيم & اثر مستقيم & 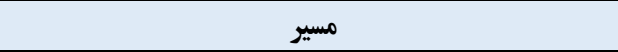 \\
\hline$<\cdot / \cdot 1$ & $F / I V$ & $\cdot / 4 \Delta$ & - &.$/ 4 \Delta$ & كفايت اجتماعى به وجدان تحصيلى \\
\hline$<\cdot / \cdot 1$ & $V / r I$ & .19 & - & .19 & اشتياق تحصيلى به وجدان تحصيلى \\
\hline$<\cdot / \cdots)$ & V/ar & .194 & - &.$/ 94$ & اشتياق تحصيلى به كفايت اجتماعى \\
\hline$<\cdot / \cdots$ & $\varphi / 1$ & $\cdot / \mathrm{AV}$ & $\cdot / A Y$ & $\cdot / 4 \Delta$ & كفايت اجتماعى به وجدان تحصيلى با ميانجى گرى اشتياق تحصيلى \\
\hline
\end{tabular}

مىشود. كفايت اجتماعى تكنيكى است كه به كمكك آن افراد مى آموزند

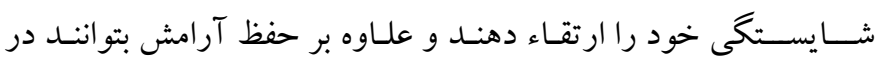

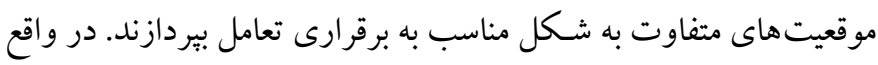

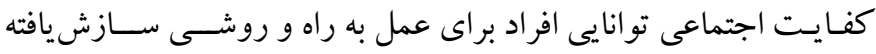

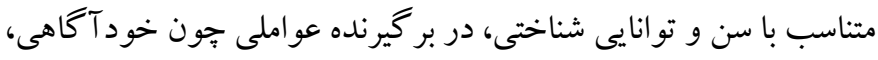

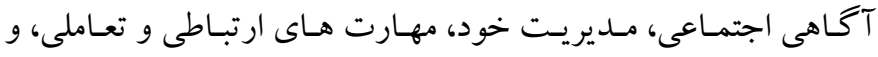

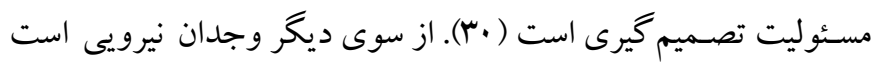

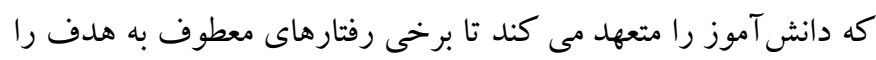

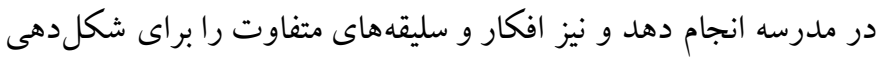

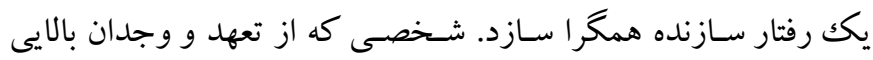
برخوردار اسـت، بر اهميت، ارزش و معناى اينكه جه كسى است و جهـ

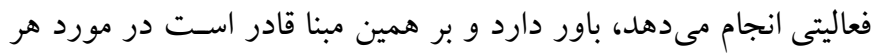

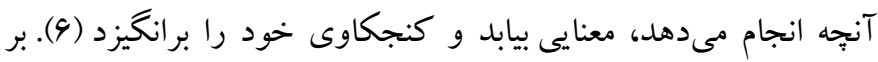
همين اسـاس در كفـايـت اجتمـاعى تعـامـل و مهارت هـاى اجتمـاعى و همجنين مسئوليت تصميم گيرى ،عاملى اصلى براى فرد به حساب مي لهى آيند كه در افراد با وجدان تحصيلى بالا نيز اين عامل ديده مى شود و آنها خود بـ بردي

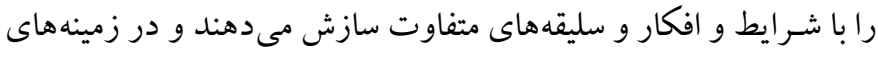
تصميم گيرى، دقت بيشتر به خرج داده و مسئوليت بيذيرتر هستند. بنابر اين

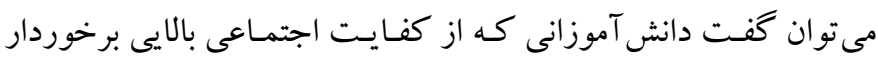
هستند به تناسب، وجدان تحصيلى آنان نيز بالاتر است. همجينين در تبيين اين يـافتـه كه اشـتياق تحصـيلى مى تواند وجدان

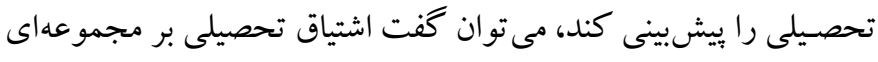

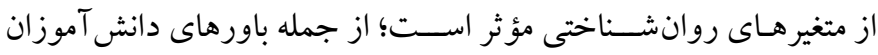

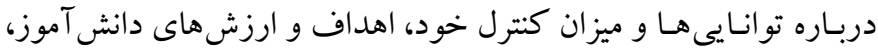
ارتباطات اجتماعى، و احسـاس تعلق وى به مدرسـهـ و دانشــاه (آم). اشـتياق شناختى به سرمايه كذارى شخصى در فعاليتهاى ياد گيرى اشاره
همجنـان كـه نتايج جدول F نشـان مىدهد مســير مســتقيم كفايت

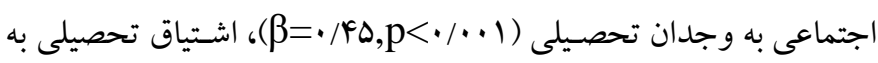

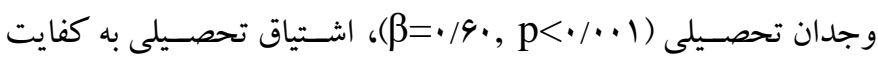

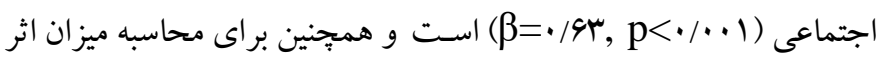

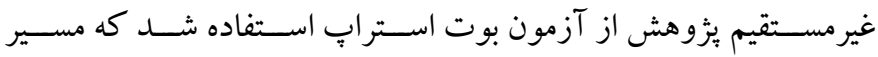
غيرمستقيم كفايت اجتماعى به وجدان تحصسيلى با ميانجى گرى اشـتياق

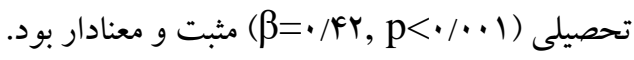

\section{بحث و نتيجه كيرى}

يزروهش حاضـر با هدف ارائه مدل سـاختارى وجدان تحصسيلى بر اسـاس

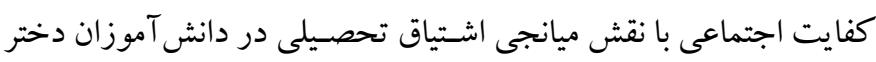
دوره متوسطه انجام شد. نتايج به طور كلى نشان داد كه مدل ييشنهادى باليا

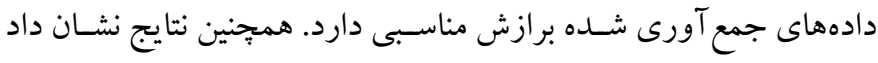
كه بين وجدان تحصـيلى با كفايت اجتماعى و اشـتياق تحصـيلى رابطه

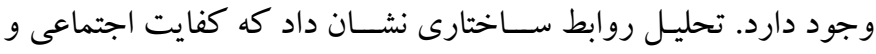

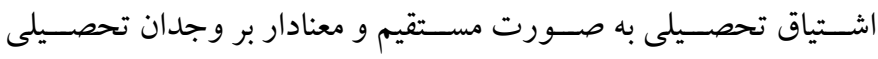

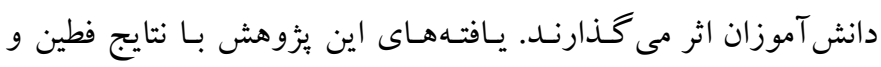

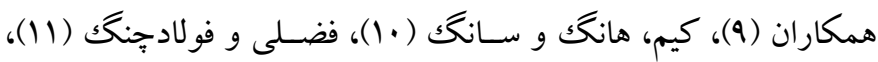

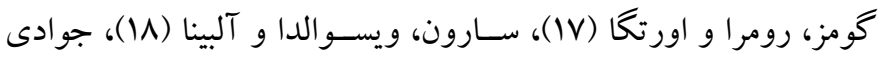
علمى و همكاران (Y\&) يالو، ماركوتيو و كاسـتيو (YN) دتو و همكاران

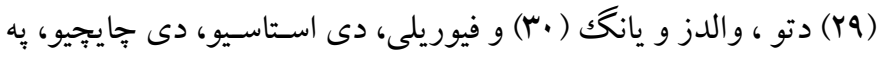

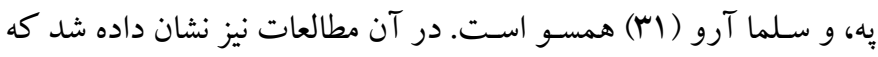
بين وجدان تحصيلى با كفايت اجتماعى و اشتياق تحصيلى دانش آموزان رابطه و جود دارد.

در تبيين اين يافته كه كفايت اجتماعى مى تواند وجدان تحصـيلى را

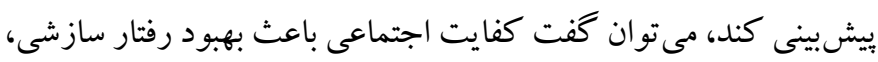

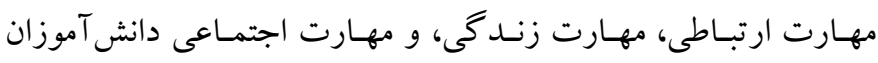


تحصـيلى با وجدان تحصـيلى رابطه دارد و كفايت اجتماعى و اشـتياق

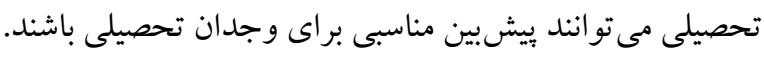

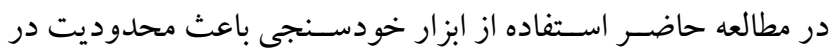

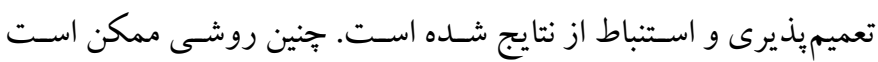

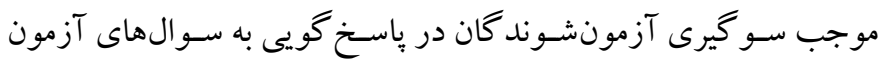

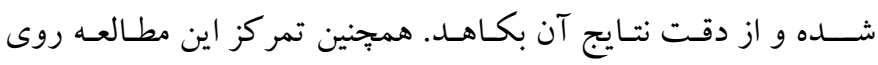

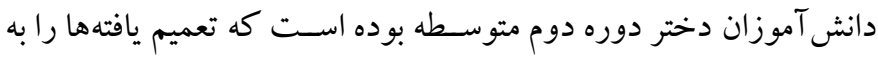

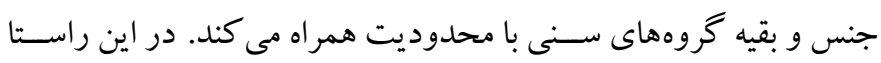

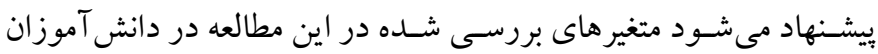
بايههاى تحصسيلى مختلف و با كنترل نقش متغيرهاى زمينهاى مانند سـن

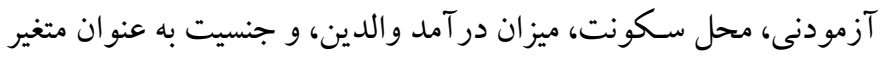

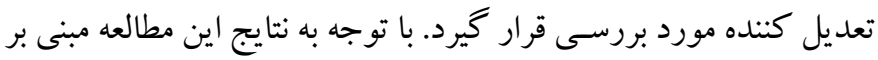

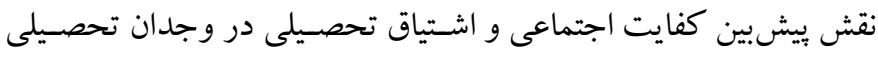
ييشـنهاد مى شـود كه در جهت افزايش وجدان تحصسيلى دانش آموزان، نقش اين دو متغير لحـاظ شــود. همجنين نتـايج اين بزوهش حساوى تلويحات كاربردى مهمى براى ارتقاى وجدان تحصيلى دانش آموزان در

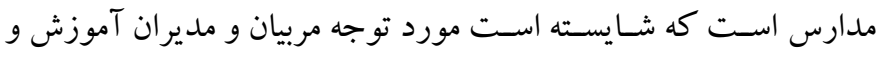

$$
\text { يرورش قرار گيرد. }
$$

\section{ملاحضات اخلاقى}

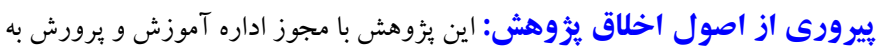

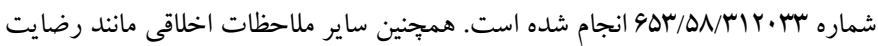

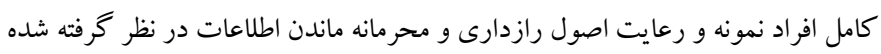

حامى مالى: اين مطالعه بدون حمايت مالى نهاد يا هر گونه سازمانى انجام شده است.

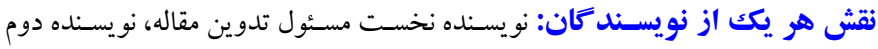

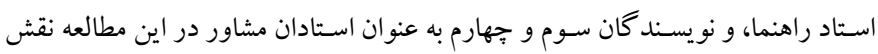

داشتهاند.

تضـاد منافع: بر اساس اعلام نويسند كان، در اين يُروهش هيج گونه تضاد منافع وجود

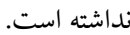
تشـكر و قدردانى: از مديريت و كار كنان اداره آموزش و برورش شهر ستان بو كان و

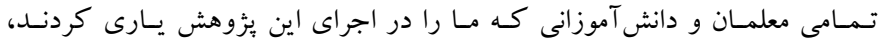

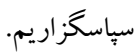

دارد كه شـامل خودتنظيمى، التزام به ياد كيرى تبحرى، و اسـتفاده از راهبردهاى ياد گيرى مانند استفاده از بسط معنايى مى شود (YF). همجنين

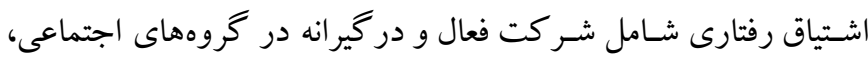
روابط كلاسـى، مطالعه در دانشــاه و خانه، فعاليتهاى فوق برنامه، داشـتن رفتارهاى مثبت، و نداشـتن رفتارهاى مخرب مىشـود. افراد با

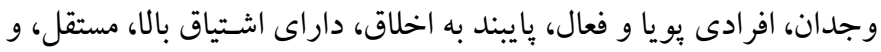
مسئوليت يُّير هستـند (V). بنابر اين دانش آموزانى كه از اشـتياق تحصيلى

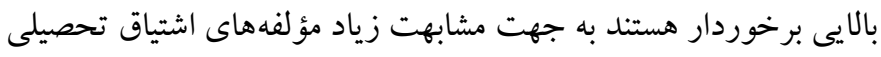
بـا مؤلفههاى موجود در وجدان تحصـيلى (مهارت شــناختى، مهارت رفتارى، و نظاير آن) مى توان اظهار كرد كه اين دانش آموزان با وجدان

$$
\text { تحصيلى بالا معرفى مى شوند. }
$$

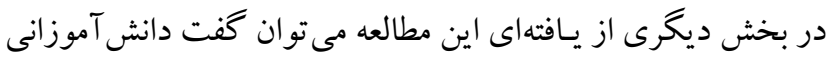

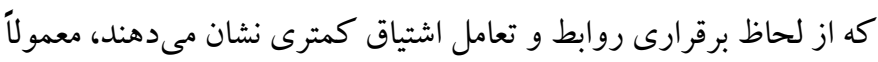

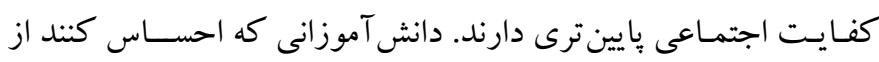

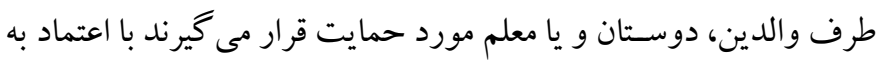
خود بالايى با تكاليف مدرسه مواجه شده و با كشاكش هاى مدرسه انطباق

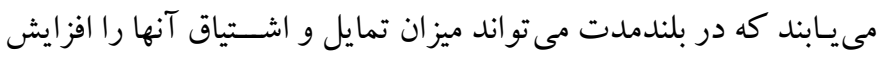

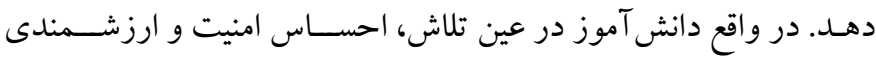
مى كند و مدرسه را به عنوان يكك محيط امن و حامى در كك مى كند ( آس).

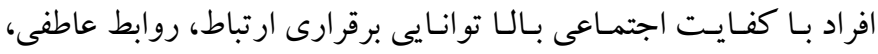

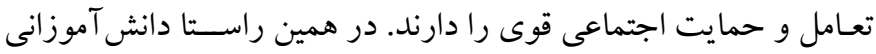
كه تعامل و روابط مثبتى با گروه هاى همسالان و معلمان خود در مدرسه

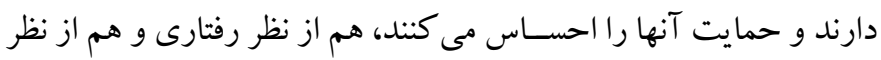
شـناختى اشـياق بيشـترى به مدرسـه خواهند داشـت (·r). اشـتياق بالا در دانش آموزان، آنها را به برقرارى روابط دوســتانه، تعامل با اطرافيان و

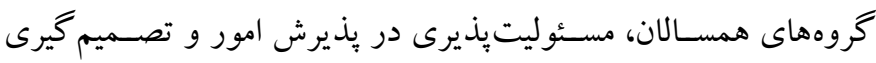

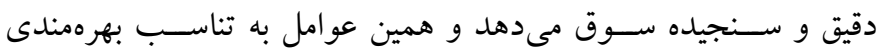

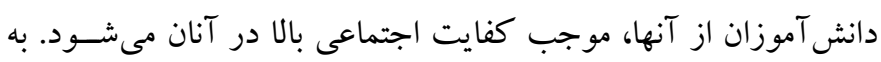

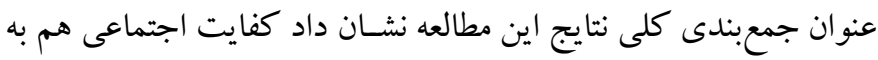

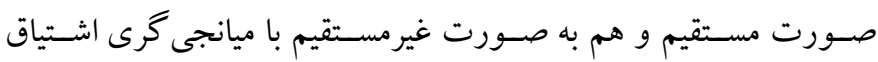

\section{References}


1. You S, Dang M, Lim S A. Effects of student perceptions of teachers' motivational behavior on reading, English, and mathematics achievement: The mediating role of domain specific self-efficacy and intrinsic motivation. Child \& Youth Care Forum. 2016; 45(2): 221-240. [Link]

2. Rostamogli Z, Khoshnoodnia Chomachaei B. Comparing academic conscientiousness and academic burnout in students with and without learning disabilities. Journal of Learning Disabilities. 2013; 2(3): 18-37. [Persian]. [Link]

3. Di Fabio A, Busoni L. Fluid intelligence, personality traits and scholastic success: Empirical evidence in a sample of Italian high school students. Personality and Individual Differences. 2007; 43(8): 2095-2104. [Link]

4. Higgins DM, Peterson JB, pihl RO, Lee AGM. Prefrontal cognitiveability, intelligence, big five personality, and the prediction of advanced academic andworkplace performance. J of Personality and Social Psychology. 2007; 93(2): 298-319. [Link]

5. Meyer JP, Herscovitch L. Commitment in the workplace: Toward a general model. Human resource management review. 2001; 11(3): 299-326. [Link]

6. Kabini Moghaddam S, Entesar Foumani GhH, Hejazi M, Asadzadeh H. The effectiveness of self-directed learning strategy training in increasing the academic vitality and academic conscientiousness of procrastinating students. Journal of Educational Psychology. 2019; 14 (50): 171-193. [Link]

7. McIllory D, Bunting B. Personality, behavior, and academic achievement: Principles for educators to inculcate student to model. Contemp Educ Psychol. 2002; 27(2): 326337. [Link]

8. Komar S, Brown DJ, Komar JA, Robie C. Faking and the validity of conscientiousness: A Monte Carlo investigation. Journal of Applied Psychology. 2008; 93(1): 140. [Link]

9. Fetin Sh, Hosseinian S, Asgharnejad F, Abolmaali Kh. Evaluation of the role model of social problem-solving skills and illegitimate capital on academic burnout mediated by academic conscientiousness and academic help seeking. J Positive Psychology. 2021; 16 (56): 31-56. [Persian]. [Link]

10. Kim HJ, Hong AJ, Song HD. The roles of academic engagement and digital readiness in students' achievements in university e-learning environments. Int J Educ Technol High Educ. 2019; 16: 21. [Link]

11. Fazli A, Foolad Chang M. The relationship between academic ecstasy and academic burnout: the mediating role of development goals. J Education Strategies in Medical Sciences. 2020; 12 (3): 85-96. [Persian]. [Link]
12. Kirkovski M, Enticott PG, Fitzgerald PB. A review of the role of femalegender in autism spectrum disorders. J Autism Dev Disord. 2013; 43(11):2584-603. [Link]

13. Gresham F, Elliot, S. Assessment and classification of children's social skills: A review of methods and issues. Journal of School Psychology Review. 1984; 13(3): 292301. [Link]

14. Jafari Baghkheirati A, ghahramani L, keshavarzi S, Kaveh M H. The Effect of Optimism Training Through Educational Movies on the Students' Social Competence. Iran J Health Educ Health Promot. 2014; 2 (1) :57-64. [Persian]. [Link]

15. Dasht Bozorgi Z, Shamshirgaran M. The effectiveness of positivity training on social adequacy and health resilience in nurses. J Positive Psychology. 2019; 4 (2): 13-24. [Persian]. [Link]

16. Felner RD, Lease AM, Phillips RS. Social competence and the language of adequacy as a subject matter for psychology: A quadripartite tri-level framework. In T. P. Gullota, G. R. Adams, \& R. Montemayor (Eds.), The development of social competence in adolescence (pp. 254264). Beverly Hills, CA: Sage. 1990; pp. 254-264.

17. Gómez-Ortiz O, Romera EM, Ortega-Ruiz R. Multidimensionality of social competence: Measurement of the construct and its relationship with bullying roles. Journal of Psych Didactics. 2017; 22: 37-44. [Link]

18. Sarune ML, Visvaldas L, Albina K. Teacher perceptions of student social competence and school adjustment in elementary school, Cogent Psychology. 2018; 5:1-15. [Link]

19. Bavi S. Comparison of the effectiveness of social adequacy training and social restraints on social anxiety, social adjustment and social intimacy of adolescent boys. J Social Psychology. 2020; 13 (53): 37-46. [Persian]. [Link]

20. Beyrami M, Hashemi Nosratabad T, Badri Gargari R, Dabiri S. The effectiveness of social adequacy training based on Felner model on social adjustment of bullying students according to the type of orientation of social goals. Clinical Psychology Studies. 2017; 23 (1): 1-24. [Persian]. [Link]

21. Alduncin N, Lynne C, Huffman M, Feldman ML. Executive function is associated with social competence in preschoolaged children born preterm or full term. Early Human Development. 2014; 90(6): 299- 306. [Link]

22. Naami AZ, Piriaei S. Relationship between the dimensions of motivation education and enthusiasm education of third year high school students in Ahvaz. J Research in Educational Systems. 2013; 16 (6): 42-29. [Persian]. [Link]

23. Sukor ShA, Yusoffb NM, Ghazalic IM, Osmand RH, Dzahir NFM. The Relationship between lecturers teaching style And Academic Engagement. Social and Behavioral Sciences. 2014; 118(3): 10-20. [Link] 
24. Fredricks JA, Blumenfeld PC, Paris AH. School engagement: potential of the concept, state of the evidence. Review of Educational Research. 2004; 74(1): 59-109. [Link]

25. Wang MT, Holcombe R. Adolescents' perceptions of classroom environment, school engagement, and academic achievement. American Educational Research Journal. 2010; 47(3): 633-662. [Link]

26. Javadi Elmi Leila, Asadzadeh H, Delavar A, Dortaj F. Modeling the structural relationships of students' academic motivation based on transformational teaching, academic self-efficacy mediated by the role of academic vitality. BiQuarterly J Cognitive Strategies in Learning. 2020; 8 (14): 1-19. [Persian]. [Link]

27. Upadaya K, Salmela-Aro K. "Development of school engagement in association with academic success and wellbeing in varying social contexts. A review of empirical research". European Psychologist, 2013, 18(2), 136-14. [Link]

28. Paloș, R., Maricuţoiu, L. P., \& Costea, I. Relations between academic performance, student engagement and student burnout: a cross-lagged analysis of a two-wave study. Studies in Educational Evaluation, 2019, 60, 199204. [Link]

29. Datu, J A, King R, Valdez J P. The academic rewards of socially-oriented happiness: Interdependent happiness promotes academic engagement. Journal of School Psychology, 2017, 61, 19-31. [Link]

30. Datu, J. A. D. Valdez, J.P.M. Yang W. The academically engaged life of mastery-oriented students: Causal ordering among positive emotions, mastery-approach goals, and academic engagement. Revista de Psicodidáctica, 2021, 17, 17-26. [Link]

31. Fiorilli, C., De Stasio, S., Di Chiacchio, C., Pepe, A., \& Salmela-Aro, K. School burnout, depressive symptoms and engagement: Their combined effect on student achievement. International Journal of Educational Research, 2017, 84, 1-12. [Link]

32. Guadagnoli E, Velicer WF. Relation of sample size to the stability of component patterns. Psychol Bull.1988, 103(2):265-75. [Link]

33. Parandian SH. Construct social self- competency questionnaire and its normalization of teenagers in Tehran city. [MSc. thesis]. Tehran: Allameh Tabatabai University; 2006. [Persian].

34. Abbasi M, Dargahi Sh, Pirani Z, Bonyadi F. The role of procrastination and motivational self-regulation in predicting students' academic achievement. Iranian Journal of Medical Education. 2016; 15 (23): 160-169. [Persian]. [Link] 